Check for updates

Cite this: RSC Adv., 2020, 10, 6030

Received 26th November 2019

Accepted 30th January 2020

DOI: 10.1039/dOra00853b

rsc.li/rsc-advances

\section{Direct use of 1,3-dienes for the allylation of ketones via catalytic hydroindation $\uparrow$}

\author{
Itaru Suzuki, (D) a Kensuke Yagi, ${ }^{b}$ Shinji Miyamoto ${ }^{a}$ and Ikuya Shibata*a \\ In this study, in situ catalytically generated allylic indium from 1,3 dienes and $\operatorname{lnCl}_{2} \mathrm{H}$ was developed for use in \\ the allylation of ketones. This protocol resulted in the unprecedented establishment of a successive \\ combining of quaternary $\mathrm{C}-\mathrm{C}$ bonds, which could then be applied to many types of ketones. Other \\ branched 1,3 dienes and vinyl cyclopropanes, could also be coupled with ketones in a reaction where \\ $\mathrm{CuH}$ would not be applicable.
}

Homoallylic alcohols are useful building blocks in the synthesis of bioactive natural compounds and pharmaceuticals. For these syntheses, the preparation of tertiary compounds has remained challenging regardless of whether or not they are given asymmetrically. ${ }^{1}$ The allylation of ketones with allylic reagents is a typical method for the preparation of these compounds (Scheme 1a). ${ }^{2}$ This method, however, cannot avoid wasteful steps such as the transmetalation between Grignard reagents and $\mathrm{B}, \mathrm{Si}$ or Sn sources and the reductive generation between allylic halides and low-valent metals. Although this method can be applied to highly stereocontrolled reactions, the wasteful steps are cumbersome and more practical reaction methods are required.

For this process, 1,3-dienes are an important industrial feedstock that is produced on a massive scale via either the cracking of ethylenes or the transformation of biomass. Easily available dienes have recently replaced the conventional allylation of aldehydes with the aid of transition metal catalysts (Scheme 1b). ${ }^{3}$ After the first application using a Ti catalyst by Gendre and Moïse, ${ }^{4}$ Krische has expanded the field with the introduction of Ru-catalyzed stereocontrolled reactions. ${ }^{5}$ Other transition metals such as $\mathrm{Ni}^{6}{ }^{6} \mathrm{Ir},{ }^{7}$ and $\mathrm{Rh}^{8}$ have contributed to improvements in coupling. A recent adoption of ketones as viable substrates was achieved by Liu and Buchwald via proficient $\mathrm{Cu}-\mathrm{H}$ chemistry. ${ }^{9}$ The scope of possible substrates could be expanded even further, ${ }^{10}$ however, particularly with the use of 1,3-dienes and ketones that possess a variety of functional groups.

Our group has explored the hydrostannylation ${ }^{11}$ or indation $^{12}$ of unsaturated bonds in the preparation of reactive

${ }^{a}$ Research Center for Environmental Preservation, Osaka University, 2-4 Yamadaoka, Suita, Osaka 565-0871, Japan. E-mail: shibata@epc.osaka-u.ac.jp

${ }^{b}$ Division of Applied Chemistry, Graduate School of Engineering, Osaka University, 2-1, Yamadaoka, Suita, Osaka 565-0871, Japan

$\dagger$ Electronic supplementary information (ESI) available. See DOI: $10.1039 /$ d0ra00853b organostannanes or indiums that could be applied to further transformations, although stoichiometric amounts of Sn or In sources must be added to the reaction systems. Recently, a transition metal-free reductive coupling of 1,3 -dienes, ${ }^{13}$ or their derivatives such as vinyl cyclopropanes,${ }^{14}$ with aldehydes catalyzed by $\mathrm{Bu}_{2} \mathrm{SnXH}$ has been developed, but the method would not allow the use of ketones due to the low reactivity of the reaction intermediate, allylic stannanes (Scheme 1c). On the other hand, our group has already developed a process for the hydroindation of 1,3-dienes with a stoichiometric amount of $\mathrm{InX}_{2} \mathrm{H}$ to give allylic indiums followed by the allylation of ketones. ${ }^{12 b, 12 d}$ Herein, we report the catalytic coupling of 1,3dienes or vinyl cyclopropanes with ketones through the generation of allylic indiums via the hydroindation of 1,3-dienes with a catalytic amount of $\mathrm{InX}_{2} \mathrm{H}$ (Scheme 1c).

We initiated the optimization of the reaction conditions by combining 1,3-butadiene (1a) and acetophenone (2a) in a sealed test tube (Table 1). The gaseous diene 1a was liquefied and weighed before addition to the reaction. Based on our previous reports, $\mathrm{InCl}_{2} \mathrm{OMe}$ generated from $\mathrm{InCl}_{3} / \mathrm{NaOMe}$ and a silane were chosen as indium and hydride sources, respectively. ${ }^{13}$ The desired product 3aa was obtained in a $92 \%$ yield as a mixture of

(a)

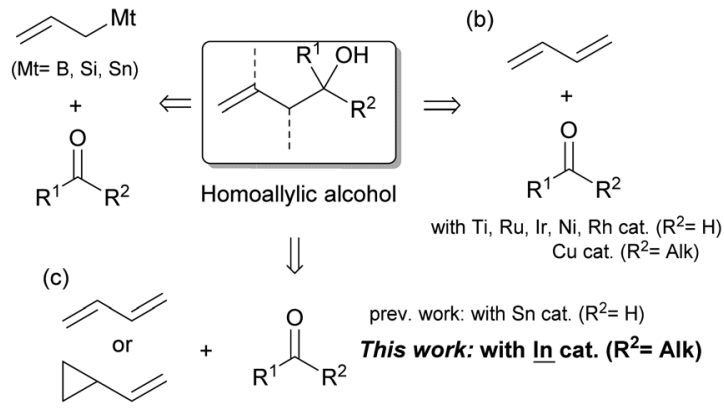

Scheme 1 Synthesis of homoallylic alcohols from allylation reagents with ketones. 
Table 1 Optimization of the reaction conditions ${ }^{a}$

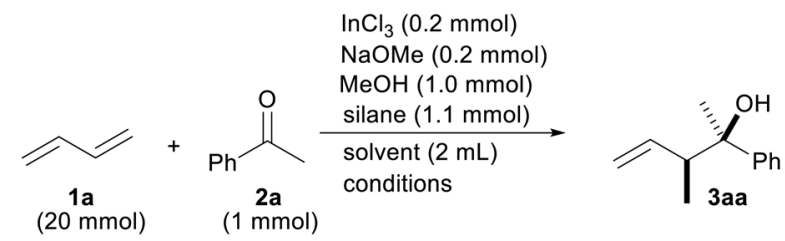

\begin{tabular}{|c|c|c|c|c|}
\hline Entry & Silane & Solvent & Conditions & $\begin{array}{l}\text { Yield }(\%) \\
\text { 3aa }(\text { syn : anti })^{b}\end{array}$ \\
\hline 1 & $\mathrm{MePhSiH}_{2}$ & THF & $25^{\circ} \mathrm{C}, 48 \mathrm{~h}$ & $92(80: 20)$ \\
\hline 2 & & & $25^{\circ} \mathrm{C}, 48 \mathrm{~h} \mathrm{w} / \mathrm{o} \mathrm{MeOH}$ & $42(88: 12)$ \\
\hline 3 & & & $25{ }^{\circ} \mathrm{C}, 24 \mathrm{~h}$ w/o $\mathrm{MeOH}$ & $54(76: 24)$ \\
\hline 4 & $\mathrm{Et}_{3} \mathrm{SiH}$ & THF & $25^{\circ} \mathrm{C}, 24 \mathrm{~h}$ & $12^{c}$ \\
\hline 5 & $\mathrm{Ph}_{3} \mathrm{SiH}$ & THF & $25^{\circ} \mathrm{C}, 24 \mathrm{~h}$ & 0 \\
\hline 6 & $\mathrm{Ph}_{2} \mathrm{SiH}_{2}$ & THF & $25^{\circ} \mathrm{C}, 24 \mathrm{~h}$ & $32(83: 17)$ \\
\hline 7 & $\mathrm{PhSiH}_{3}$ & THF & $25^{\circ} \mathrm{C}, 24 \mathrm{~h}$ & $54(83: 17)$ \\
\hline 8 & $\mathrm{MePhSiH}_{2}$ & THF & $60^{\circ} \mathrm{C}, 3 \mathrm{~h}$ & $92(80: 20)$ \\
\hline 9 & & $\mathrm{MeCN}$ & & $38(80: 20)$ \\
\hline 10 & & $\mathrm{Et}_{2} \mathrm{O}$ & & $71(76: 42)$ \\
\hline 11 & & Toluene & & $9^{c}$ \\
\hline 12 & & THF & w/o NaOMe & Trace \\
\hline 13 & & & w/o $\mathrm{InCl}_{3}$ & 0 \\
\hline 14 & & & With TEMPO (0.2 mmol) & 0 \\
\hline 15 & & & With $\mathrm{InCl}_{2} \mathrm{OMe}(0.1 \mathrm{mmol})$ & $51(78: 22)$ \\
\hline
\end{tabular}

${ }^{a}$ The yields were determined by ${ }^{1} \mathrm{H}$ NMR. ${ }^{b}$ Stereochemistry, see: ref. $15 .{ }^{c} \mathrm{dr}$ could not be determined because of complex of the reaction mixture.

the diastereomers (entry 1). The yield was lowered either when no $\mathrm{MeOH}$ was used or when the reaction time was cut by half (entries 2 and 3). A screening of the silanes showed that $\mathrm{MePhSiH}_{2}$ was the optimal hydride source (entries 4-7). We found that the reaction was finished in $3 \mathrm{~h}$ when the reaction temperature was raised to $60{ }^{\circ} \mathrm{C}$ (entry 8). Replacing the solvent with $\mathrm{MeCN}, \mathrm{Et}_{2} \mathrm{O}$ or toluene did not improve the reaction yield (entries 9-11). It was necessary to add $\mathrm{NaOMe}$ to the reaction system for a facile generation of $\mathrm{InCl}_{2} \mathrm{H}$ (entry 12). ${ }^{\mathbf{1 6}}$ It was important to add $\mathrm{InCl}_{3}$ to the reaction (entry 13). A radical scavenger, TEMPO, suppressed the progress of the reaction, which implied that this reaction contains a radical process (entry 14). The reaction yield was decreased when the lower amount of the catalyst was employed (entry 15).

With the optimal reaction conditions in hand (Table 1 , entry 8), the scope of the ketones was investigated (Table 2). Electron-deficient substitution on the phenyl ring had a small effect on the reaction yield, but an electron-rich substitution decreased it appreciably (entries 2-6). The efficiency was also attenuated by steric hindrance around the $\mathrm{C}=\mathrm{O}$ moiety of propiophenone $(\mathbf{2 g})$ and butyrophenone (2h) (entries 7 and 8). $\alpha$-Cyano and -bromo acetophenone $2 \mathbf{i}$ and $2 \mathbf{j}$, respectively, reacted sufficiently (entries 9 and 10). The tolerance to reduction of the $\mathrm{C}-\mathrm{Br}$ bond by $\operatorname{InX}_{2} \mathrm{H}$ under reductive conditions is a characteristic of coupling (entries 3 and 10). ${ }^{17}$ On the other hand, $\alpha$-methoxy one was unsatisfactory as a reactant probably due to chelation between the OMe and $\mathrm{C}=\mathrm{O}$ groups with the catalyst that would have promoted a reduction in the ketone $2 \mathbf{k}$ (entry 11$)$. $\beta$-Keto ester 21 was a good partner even though a similar chelation involving two $\mathrm{C}=\mathrm{O}$ groups could have happened (entry 12). Both acyclic and cyclic aliphatic ketones were allylated (entries 13-14). Other aromatic rings such as naphthalenes were introduced into the products 3ao and 3ap (entries 15 and 16).

Reductive coupling was then applied to other dienes (Scheme 2). In the case of isoprene (1b), two different products, $\mathbf{3 b a}$ and $\mathbf{3} \mathbf{b} \mathbf{b a}^{\prime}$, were formed even though the reaction was very slow (eqn (1)). The regioselectivity derived from the different structures of the allylic indiums. To our delight, diene 1c made it possible to establish contiguous quaternary $\mathrm{C}-\mathrm{C}$ bonds with ketones 2a-2c (eqn (2)). To date, construction of contiguous quaternary $\mathrm{C}-\mathrm{C}$ bonds with a catalyst remains a challenging task in organic synthesis, ${ }^{18}$ and the task has never been realized by the same type of reductive coupling that is catalyzed by transition metal catalysts.

Our proposal of the reaction mechanism is described in Scheme 3. Initially, prepared $\mathrm{InCl}_{2}(\mathrm{OMe})$ is reduced by $\mathrm{MePhSiH}_{2}$ to give $\mathrm{HInCl}_{2}$. The indium radical is formed in the presence of tiny amounts of $\mathrm{O}_{2}$ and adds to diene $1 \mathbf{1 a}^{\mathbf{1 7}}$ The stable allylic radical A extracts hydrogen from $\mathrm{InCl}_{2} \mathrm{H}$ to afford allylic indium $\mathbf{B}$, which regenerates the indium radical. Following the allylation of ketone 2, the generated indium alkoxide $3^{\prime}$ is protonated by $\mathrm{CH}_{3} \mathrm{OH}$ to give the product 3 and $\mathrm{InCl}_{2}(\mathrm{OMe})$. The reaction mechanism was investigated using a deuterated silane, $\mathrm{Ph}_{2} \mathrm{SiD}_{2}$ (Scheme 4). We found that the 
Table 2 Scope of ketones ${ }^{a}$

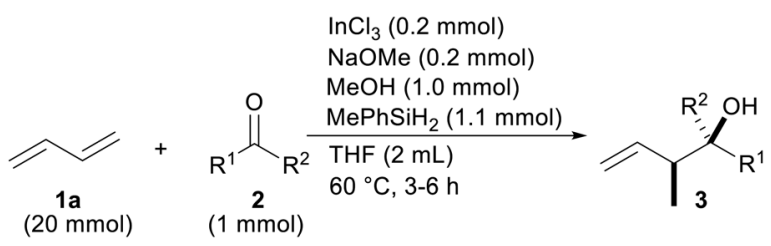

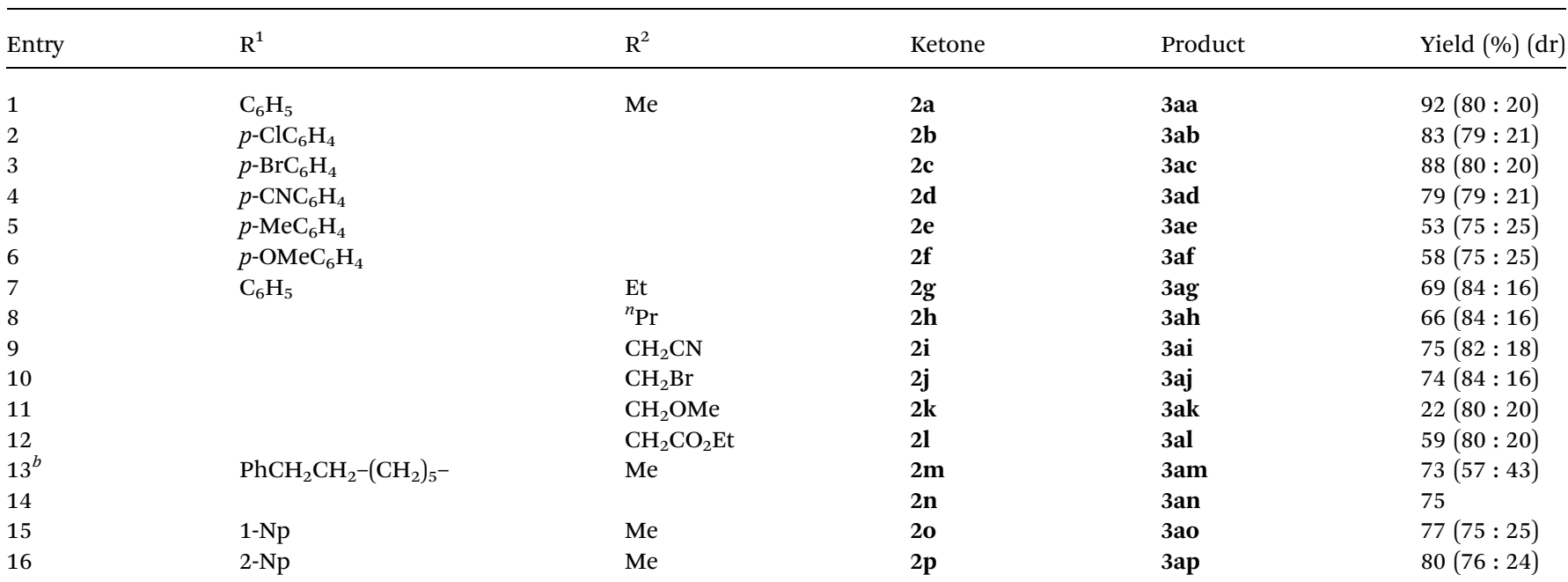

${ }^{a}$ The yields were determined by ${ }^{1} \mathrm{H}$ NMR. ${ }^{b}$ Reaction time was $24 \mathrm{~h}$.

product 3aa- $\mathbf{C H}_{2} \mathbf{D}$ was afforded without any other deuterated compound. The product $\mathbf{3} \mathbf{a} \mathbf{a}-\mathbf{C H}_{\mathbf{2}} \mathbf{D}$ is formed from $\delta$-deuterated intermediate B- $\boldsymbol{d}_{\mathbf{1}}$ as shown in Scheme 4 . Further investigation on the reaction mechanism is ongoing in our laboratory.

Finally, vinyl cyclopropane 4, a diene derivative, was tested for reductive coupling with ketones. ${ }^{19}$ The desired product $\mathbf{5 a}$ was produced in the presence of a radical initiator, $\mathrm{V}-70 \mathrm{~L}$, even
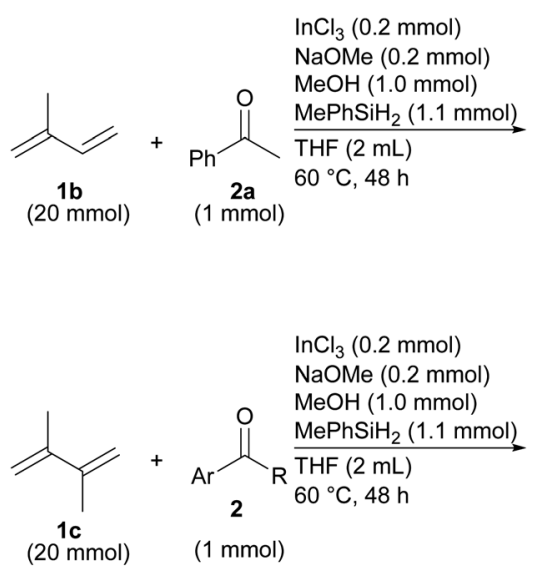

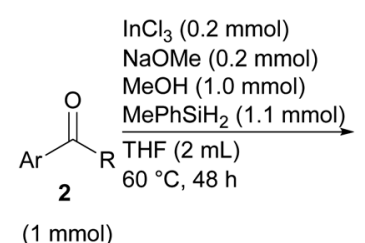

(1 $\mathrm{mmol})$

$$
\mathrm{R}=\mathrm{Me}, \mathrm{Ar}=\mathrm{C}_{6} \mathrm{H}_{5}(\mathbf{2 a})
$$$$
p-\mathrm{ClC}_{6} \mathrm{H}_{4}(2 \mathrm{~b})
$$$$
\text { p- } \mathrm{BrC}_{6} \mathrm{H}_{4} \text { (2c) }
$$$$
\mathrm{R}=\mathrm{CH}_{2} \mathrm{CN}, \mathrm{Ar}=\mathrm{C}_{6} \mathrm{H}_{5}(\mathbf{2 i})
$$$$
\mathrm{R}=\mathrm{CH}_{2} \mathrm{Br}, \quad \mathrm{C}_{6} \mathrm{H}_{5}(2 \mathrm{aj})
$$

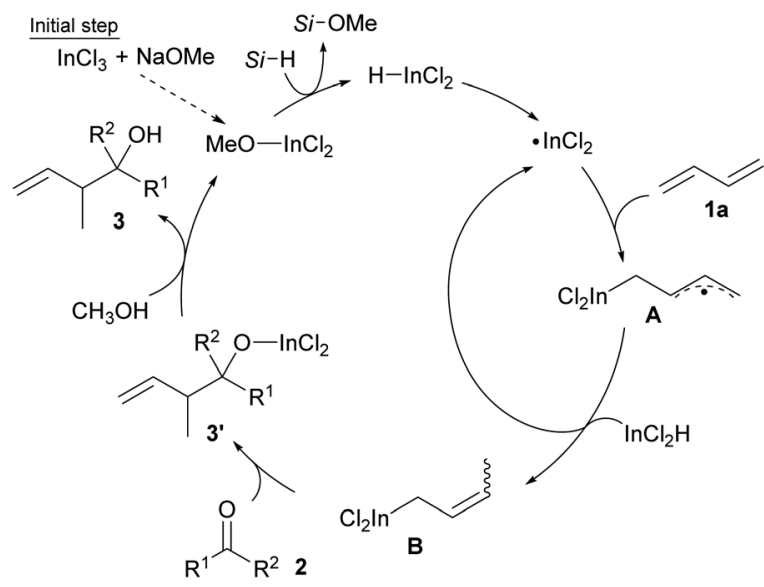

Scheme 3 A plausible catalytic cycle.

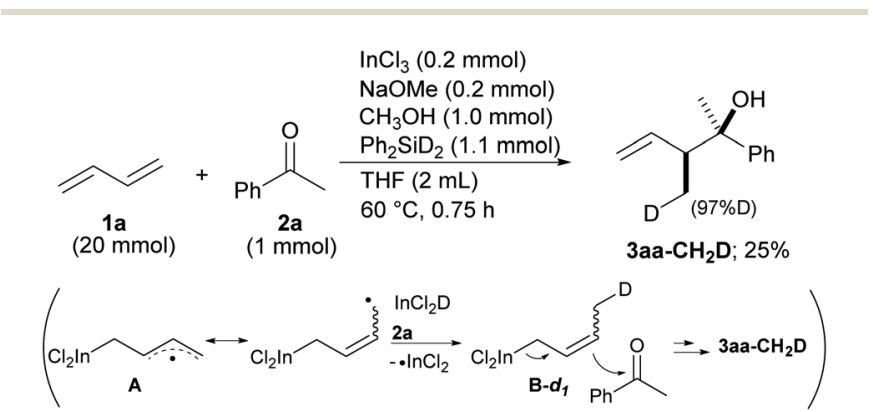

Scheme 2 Application of substituted 1,3-butadienes to the coupling.

Scheme 4 Deuterated experiments of allylation of ketone $2 a$ 


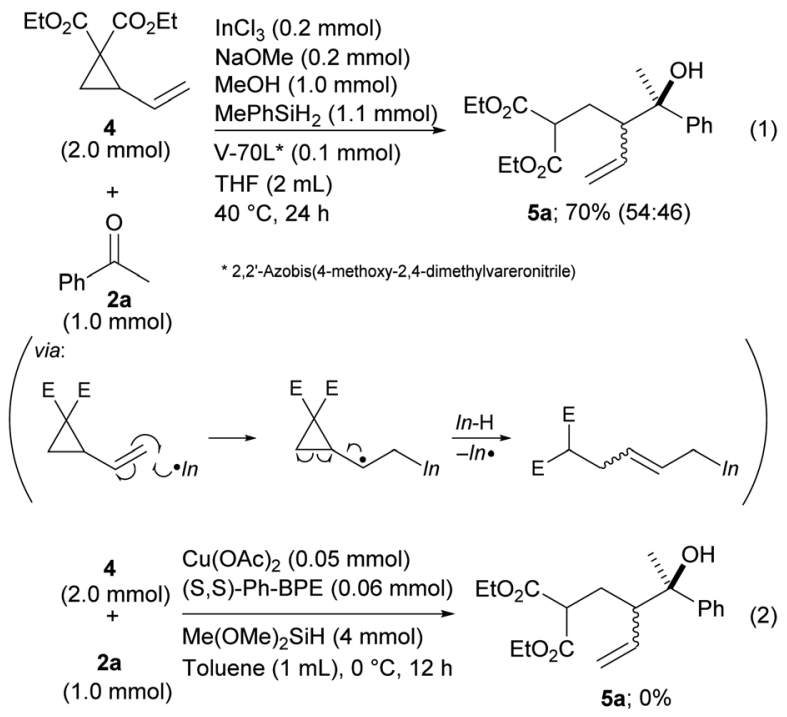

Scheme 5 Coupling of vinyl cyclopropanes with ketones.

though diastereoselectivity was not achieved (Scheme 5, eqn (1)). This could have been caused by low $E / Z$ selectivity of the allylic indiums. The seminal work developed by Buchwald that was related to a $\mathrm{Cu}-\mathrm{H}$ catalyzed reaction did not allow the use of vinyl cyclopropane as a reactant because their method has no process for a radical opening of the cyclopropane ring (Scheme 5, eqn (2)). ${ }^{9}$ Our method expands the scope of the dienes by allowing use of their derivatives.

In summary, we developed a process whereby the reductive coupling of 1,3-dienes with various ketones could be sufficiently catalyzed by $\mathrm{HInCl}_{2}$. This approach allowed the introduction of functional groups into homoallylic alcohols, which generated sequential $\mathrm{C}_{\text {tert }}-\mathrm{C}_{\text {tert }}$ bonds with expansion to vinyl cyclopropane 4. Application to an asymmetric version of the coupling and improvement of the diastereoselectivity are underway.

\section{Conflicts of interest}

There are no conflicts to declare.

\section{Notes and references}

1 M. Yus, J. C. González-Gómez and F. Foubelo, Chem. Rev., 2013, 113, 5595-5698.

2 (a) S. E. Denmark and J. Fu, Chem. Rev., 2003, 103, 27632794; (b) M. Hatano and K. Ishihara, Synthesis, 2008, 16471675; (c) Y.-L. Liu and X.-T. Lin, Adv. Synth. Catal., 2019, 361, 876-918.

3 M. Holmes, L. A. Schwartz and M. J. Krische, Chem. Rev., 2018, 118, 6026-6052.

4 L. Bareille, P. Le Gendre and C. Moïse, Chem. Commun., 2005, 775-777.

5 (a) F. Shibahara, J. F. Bower and M. J. Krische, J. Am. Chem. Soc., 2008, 130, 6338-6339; (b) J. R. Zbieg, J. Moran and M. J. Krische, J. Am. Chem. Soc., 2011, 133, 10582-10586; (c) J. R. Zbieg, E. Yamaguchi, E. L. McInturff and M. J. Krische,
Science, 2012, 336, 324-327; (d) E. L. McInturff, E. Yamaguchi and M. J. Krische, J. Am. Chem. Soc., 2012, 134, 20628-20631; (e) B. Y. Park, T. P. Montgomery, V. J. Garza and M. J. Krische, J. Am. Chem. Soc., 2013, 135, 16320-16323; (f) T.-Y. Chen and M. J. Krische, Org. Lett., 2013, 15, 2994-2997; (g) J. C. Leung, L. M. Geary, T.-Y. Chen, J. R. Zbieg and M. J. Krische, J. Am. Chem. Soc., 2012, 134, 15700-15703.

6 (a) K. M. Miller and T. F. Jamison, Org. Lett., 2005, 7, 30773080; (b) M. Kimura, A. Ezoe, M. Mori, K. Iwata and Y. Tamaru, J. Am. Chem. Soc., 2006, 128, 8559-8568; (c) S. Ogoshi, K.-i. Tonomori, M.-a. Oka and H. Kurosawa, J. Am. Chem. Soc., 2006, 128, 7077-7086; (d) A. Köpfer, B. Sam, B. Breit and M. J. Krische, Chem. Sci., 2013, 4, 1876-1880.

7 (a) J. F. Bower, R. L. Patman and M. J. Krische, Org. Lett., 2008, 10, 1033-1035; (b) J. R. Zbieg, T. Fukuzumi and M. J. Krische, Adv. Synth. Catal., 2010, 352, 2416-2420; (c) K. D. Nguyen, D. Herkommer and M. J. Krische, J. Am. Chem. Soc., 2016, 138, 14210-14213.

8 (a) M. Kimura, D. Nojiri, M. Fukushima, S. Oi, Y. Sonoda and Y. Inoue, Org. Lett., 2009, 11, 3794-3797; (b) H.-Y. Jang, R. R. Huddleston and M. J. Krische, Angew. Chem., Int. Ed., 2003, 42, 4074-4077.

9 C. Li, R. Y. Liu, L. T. Jesikiewicz, Y. Yang, P. Liu and S. L. Buchwald, J. Am. Chem. Soc., 2019, 141, 5062-5070.

10 B. Fu, X. Yuan, Y. Li, Y. Wang, Q. Zhang and T. Xiong, Org. Lett., 2019, 21, 3576-3580.

11 (a) I. Shibata, T. Suwa, K. Ryu and A. Baba, J. Am. Chem. Soc., 2001, 123, 4101-4102; (b) N. Hayashi, K. Kusano, S. Sekizawa, I. Shibata, M. Yasuda and A. Baba, Chem. Commun., 2007, 4913-4915; (c) N. Hayashi, Y. Hirokawa, I. Shibata, M. Yasuda and A. Baba, J. Am. Chem. Soc., 2008, 130, 2912-2913; (d) I. Shibata, T. Suwa, K. Ryu and A. Baba, J. Org. Chem., 2001, 66, 8690-8692.

12 (a) A. Baba and I. Shibata, Chem. Rec., 2005, 5, 323-335; (b) N. Hayashi, H. Honda, M. Yasuda, I. Shibata and A. Baba, Org. Lett., 2006, 8, 4553-4556; (c) N. Hayashi, Y. Hirokawa, I. Shibata, M. Yasuda and A. Baba, Org. Biomol. Chem., 2008, 6, 1949-1954; (d) N. Hayashi, H. Honda, I. Shibata, M. Yasuda and A. Baba, Synlett, 2008, 1407-1411.

13 I. Suzuki, Y. Uji, S. Kanaya, R. Ieki, S. Tsunoi and I. Shibata, Org. Lett., 2017, 19, 5392-5394.

14 S. Tsunoi, Y. Maruoka, I. Suzuki and I. Shibata, Org. Lett., 2015, 17, 4010-4013.

15 P. Dey, M. Koli, D. Goswami, A. Sharma and S. Chattopadhyay, Eur. J. Org. Chem., 2018, 1333-1341.

16 N. Hayashi, I. Shibata and A. Baba, Org. Lett., 2005, 7, 30933096.

17 K. Inoue, A. Sawada, I. Shibata and A. Baba, Tetrahedron Lett., 2001, 42, 4661-4663.

18 (a) K. Ohmatsu, N. Imagawa and T. Ooi, Nat. Chem., 2013, 6, 47; (b) A. Khan, L. Yang, J. Xu, L. Y. Jin and Y. J. Zhang, Angew. Chem., Int. Ed., 2014, 53, 11257-11260; (c) X. Liu, J. Zhang, L. Zhao, S. Ma, D. Yang, W. Yan and R. Wang, J. Org. Chem., 2015, 80, 12651-12658; (d) X. Huang, S. Wu, W. Wu, P. Li, C. Fu and S. Ma, Nat. Commun., 2016, 7, 12382; (e) F. I. Amr, C. Vila, G. Blay, M. C. Muñoz and 
J. R. Pedro, Adv. Synth. Catal., 2016, 358, 1583-1588; (f) S. Nakamura, R. Yamaji and M. Iwanaga, Chem. Commun., 2016, 52, 7462-7465; (g) L. Ye, Q.-S. Gu, Y. Tian, X. Meng, G.-C. Chen and X.-Y. Liu, Nat. Commun., 2018, 9, 227; $(h)$ J. C. Hethcox, S. E. Shockley and B. M. Stoltz, Angew. Chem., Int. Ed., 2018, 57, 8664-8667; (i) W.-L. Chan, X. Tang, F. Zhang, G. Quek, G.-J. Mei and Y. Lu, Angew.
Chem., Int. Ed., 2019, 58, 6260-6264; (j) M. Sun, J.-F. Chen, S. Chen and C. Li, Org. Lett., 2019, 21, 1278-1282.

19 Ir-catalyzed coupling of vinylcyclopropanes with aldehydes was developed. See: J. Moran, A. G. Smith, R. M. Carris, J. S. Johnson and M. J. Krische, J. Am. Chem. Soc., 2011, 133, 18618-18621. 